\title{
Human papilloma virus vaccines awareness among female medical and dental undergraduate students
}

\author{
Vasudha Sharma ${ }^{1}$, Rachna Bachhel ${ }^{2 *}$, Navyug Raj Singh ${ }^{1}$ \\ ${ }^{1}$ Department of Pharmacology, ${ }^{2}$ Department of Physiology, Government Medical College, Amritsar, Punjab, India
}

Received: 15 September 2020

Revised: 29 October 2020

Accepted: 30 October 2020

*Correspondence:

Dr. Rachna Bachhel,

Email: rachnasidhu70@gmail.com

Copyright: $(\odot$ the author(s), publisher and licensee Medip Academy. This is an open-access article distributed under the terms of the Creative Commons Attribution Non-Commercial License, which permits unrestricted non-commercial use, distribution, and reproduction in any medium, provided the original work is properly cited.

\section{ABSTRACT}

Background: Human papilloma virus (HPV) infection is the major risk factor for cervical cancer. Pap smear is the commonest technique for early screening and diagnosis of cervical cancer.

Methods: Cross sectional study was carried out at a medical and dental institution of Punjab, India, among 84 medical and dental female undergraduate students, falling in the age group of 18-25 years using a validated and guided questionnaire. Goal of the study was to raise the attention of the underrated and unaware agenda of prevention of cervical carcinoma by available vaccines.

Results: $96.42 \%, 25 \%$, population was aware of HPV vaccination in $3^{\text {rd }}, 2^{\text {nd }}$, medical students respectively and $60.71 \%$ in $2^{\text {nd }}$ year dental students. $8.33 \%$ of the whole population $(n=84)$ was vaccinated against HPV. The main reasons of not taking the vaccination were that the students had not heard of such a vaccine followed by the cost of the vaccine.

Conclusions: Medical and dental undergraduates are not adequately aware about the HPV vaccine and are not vaccinated in large number.

Keywords: Cervarix, Cervical cancer, Gardasil, HPV, HPV vaccination, Pap smear

\section{INTRODUCTION}

Human papilloma virus (HPV) infection is the leading cause of cervical cancer (CC). ${ }^{1} \mathrm{CC}$ is the most frequent cancer in women in India.

Current Indian estimates indicate one lakh thirty two thousand new cases and seventy four thousand deaths annually, contributing nearly $1 / 3^{\text {rd }}$ of the global deaths due to cervical cancer. ${ }^{2}$

HPV are deoxy-ribonucleic acid (DNA) viruses. They have propensity for squamous epithelium of skin and mucosa. ${ }^{3}$ There are around 100 reported HPV serotypes, fitting into two categories- low risk and high-risk HPV. ${ }^{4}$

Low-risk/ non-oncogenic serotypes $(6,11,40,42,43,44$, and 54) are associated with genital warts. High risk/ oncogenic types $(16,18,31,33,35,39,45,51,52,56$ and 58) are associated with cervical, vulvar, vaginal, and anal cancers. ${ }^{5}$

HPV types 16 and 18 are the most oncogenic and type 16 is the most prevalent. ${ }^{4}$

HPV transmission correlates with sexual activity and age. $^{6}$ The incidence rises in 30-34 years of age and peaks at 55-65 years, with a median age of 38 years. $^{2}$

According to the Centers for Disease Control and Prevention (CDC), CC can be prevented with the help of available screening tests (Pap smear) and the HPV vaccine. $^{1}$ 
Current HPV vaccines are based on virus like proteins (VLPs) which are produced by HPV surface components. VLPs are non-infective because they lack the virus's DNA. The VLPs are strongly immunogenic, leading to high levels of antibody production in the body. $^{7}$

We currently have Gardasil-4, Cervarix and Gardasil-9 vaccines licensed for HPV infection. These vaccines are prophylactic and not therapeutic.

The quadrivalent (Gardasil-4) vaccine was licensed in 2006 by United States Food and Drug Adminstration (USFDA) and it gives protection against HPV types 16, $18,6,11 .{ }^{8}$ Bivalent (Cervarix) vaccine was licensed in 2009 and it protects against HPV-16, 18 infection. ${ }^{8}$

The nonavalent HPV vaccine (Gardasil-9) protecting against HPV types 16, 18, 6, 11, 31, 33, 45, 52, 58 was approved by the USFDA in $2014 .^{8}$

The primary target population for above vaccines is girls in the age range of $9-13$ years. ${ }^{9}$

WHO recommends a two dose schedule for females $<15$ years of age. Dose is $0.5 \mathrm{ml}$ and it is administered by intramuscular route at 0 and 6 months. ${ }^{10}$

If females $\geq 15$ years of age at the time of first dose, then we give a 3 -dose schedule (0, 2, 6 months). ${ }^{10}$

Catch-up vaccination is recommended for females aged 13-26 years who have not been previously vaccinated. The high cost of the vaccine is a limiting factor of its utilization.

Pap smear is the primary screening test for detection of precancerous cervical cancer lesions, hence it can screen and diagnose CC early. ${ }^{11}$

Pap smear sample is taken from the ectocervix by rotating an Ayre spatula at a $360^{\circ}$ angle. Sample is smeared onto a glass slide and fixed with $95 \%$ ethyl alcohol. Further cytopathological examination divides lesions as negative for intraepithelial neoplasia or as epithelial cell abnormalities or abnormal pap smear. Abnormal pap test requires further investigations and treatment is given based on the stage of the disease. ${ }^{11}$

The Federation of Obstetric and Gynecological Societies of India (FOGSI) guidelines suggest screening should begin from the age of 25 years. ${ }^{12}$ Women aged 30-65 years should be screened every five years and it should continue till the age of 65 years. Thereafter screening can be stopped if there are consistently negative results for the last 15 years.

Studies conducted worldwide regarding HPV vaccination awareness reflect upon the inadequate and insufficient knowledge of the layman and even medical students. We conducted this study with an objective of raising awareness of an underrated but very important preventable public health condition of cervical cancer.

\section{Aim}

To assess the awareness about HPV vaccine and its implications in cervical carcinoma in female medical and dental undergraduate students.

\section{METHODS}

This was a cross sectional study carried out at the Department of Pharmacology, at Government Medical College, Amritsar, Punjab, India.

The study subjects comprised of 84 medical and dental students, falling in the age group of less than 25 years. Students who volunteered were only included in the study. Male students and students without any medical background were excluded from the study.

A validated and guided questionnaire was distributed to the students for assessment of awareness and knowledge about HPV vaccine and its implications in cervical carcinoma. The study duration was from September $15^{\text {th }}$ to October $15^{\text {th }}, 2019$.

All the students were explained about the study and informed consent was taken before commencing the study. Data was compiled and evaluated by Microsoft excel 2010 version.

\section{RESULTS}

Figure 1 encompasses results about comparison general awareness and knowledge about HPV vaccine along with the awareness about Pap smear.

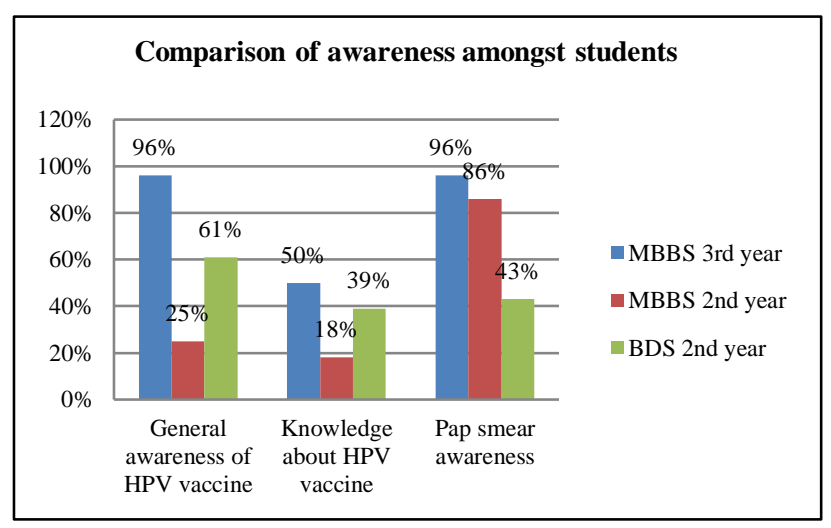

Figure 1: Comparison of general awareness, knowledge of HPV vaccine and pap smear amongst medical and dental students.

$96.42 \%$ population in $3^{\text {rd }}$ year medical students, $25 \%$ in $2^{\text {nd }}$ year medical students and $60.71 \%$ in $2^{\text {nd }}$ year dental students were aware about the HPV vaccine (Figure 1). 
$50 \%$ population in $3^{\text {rd }}$ year medical students, $18 \%$ population in $2^{\text {nd }}$ year medical students and $39.2 \%$ population in $2^{\text {nd }}$ year dental students had knowledge about HPV vaccine, including doses and route of administration of the vaccine (Figure 1).

$96.42 \%$ population in $3^{\text {rd }}$ year medical students, $85.71 \%$ in $2^{\text {nd }}$ year medical students and $42.85 \%$ in $2^{\text {nd }}$ year dental students knew about the screening test (Pap smear) for cervical cancer (Figure 1).

Nearly all the students believed HPV vaccine can prevent cervical cancer, though it is not certain if this was their answer from medical knowledge or by chance.

Vaccinated percentage in MBBS $3^{\text {rd }}$ year was $14 \%(4 / 28)$, $3.5 \%(1 / 28)$ in MBBS $2^{\text {nd }}$ year and $7 \%(2 / 28)$ in BDS $2^{\text {nd }}$ year (Figure 2).

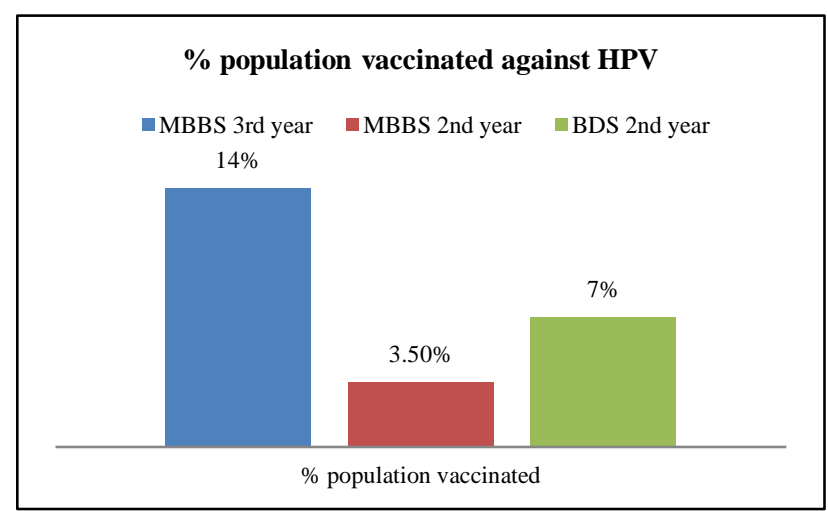

Figure 2: Percentage of population vaccinated against HPV in medical and dental students.

In total, only $8.33 \%$ of the whole population $(n=84)$ was vaccinated against HPV. Main sources of their information were health professionals, followed by senior friends.

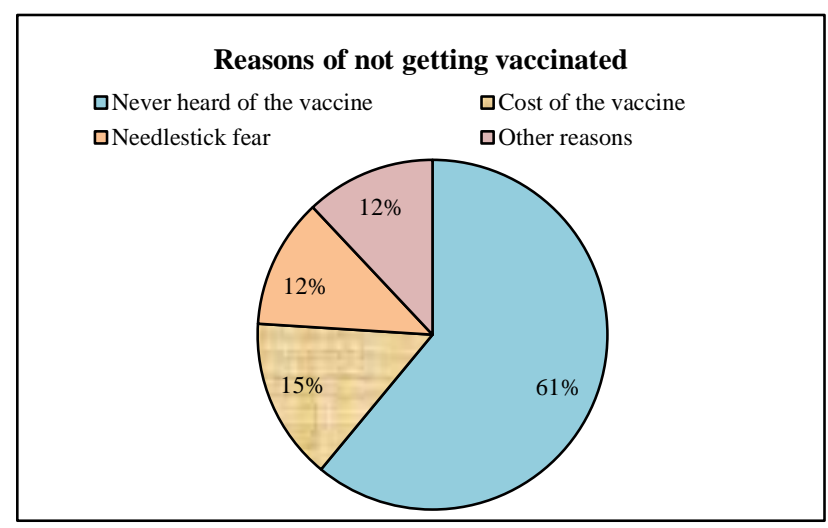

Figure 3: Reasons listed by students for not getting vaccinated against HPV.

The reasons mentioned by the students for not getting vaccinated were that the students had not heard of such a vaccine followed by its cost and needle-stick fear (Figure $3)$.

\section{DISCUSSION}

A study conducted among 1109 women in western China concluded that only $28.85 \%$ of respondents $(n=320)$ had heard of HPV; among this subgroup, only half (53.44\%) knew that it causes cervical cancer, only $26(8.13 \%)$ correctly answered all questions about HPV. ${ }^{13}$

Cross sectional study conducted by Mehta et al, amongst 150 medical students in Delhi showed that $18 \%$ students did not know about the preventive measure of cervical cancer and $50 \%$ were unaware of the HPV infection. ${ }^{14}$

In a study by Das et al 165 female medical students participated and it was concluded that overall knowledge about cervical cancer its causation and prevention was adequate only in about $40 \% .^{15}$

Singh et al conducted a cross sectional study amongst 297 medical students. They concluded that knowledge regarding cervical cancer and HPV vaccine was almost double in medical $3^{\text {rd }}$ year students than medical $2^{\text {nd }}$ year students. ${ }^{16}$

\section{CONCLUSION}

This study puts a light on the unmet need of awareness campaigns regarding cervical carcinoma and its primary prevention. Our study tried to evaluate knowledge of $2^{\text {nd }}$, $3^{\text {rd }}$ year medical and $2^{\text {nd }}$ year dental female students regarding HPV vaccination. Most of the students, but not all, of the participants in our study had awareness about the HPV vaccine. Nearly all knew about the viral etiology that leads to cervical cancer.

$3^{\text {rd }}$ year medical students seemed to be more aware and knowledgeable compared to $2^{\text {nd }}$ year medical and dental students.

Medical and dental students are not adequately knowledgeable about the HPV vaccine and are not vaccinated in large number. The non-medical professionals and layman are expected to be less aware about HPV vaccine, hence spreading awareness through public platform like pamphlets, smart phone health applications, radio, television and messaging can fill the gap.

Lastly, we conclude that the need of the hour is to spread awareness regarding HPV vaccination and organize health awareness camps in rural and urban areas to increase the number of vaccinated population. This will directly decrease the burden of cervical cancer in developing countries and in turn bring economic benefit in cancer treatment facilities in India. Cancer screening programs should be organized freely in urban/rural sectors, and 
women should be sensitized for accepting the HPV vaccines.

Funding: No funding sources

Conflict of interest: None declared

Ethical approval: The study was approved by the Institutional Ethics Committee

\section{REFERENCES}

1. Saqer A, Ghazal S, Barqawi H, Babi JA, AlKhafaji R, Elmekresh MM. Knowledge and awareness about cervical cancer vaccine (HPV) among parents in Sharjah. Asian Pac J Cancer Prev. 2017;18(5):123741.

2. Kaarthigeyan K. Cervical cancer in India and HPV vaccination. Indian $\mathrm{J}$ Med Paediatr Oncol. 2012;33(1):7-12.

3. Nigam A, Saxena P, Acharya AS, Mishra A, Batra S. HPV vaccination in India: critical appraisal. ISRN Obstet Gynecol. 2014;2014e394595.

4. Singh J, Roy B, Yadav A, Siddiqui S, Setia A, Ramesh R, et al. Cervical cancer awareness and HPV vaccine acceptability among females in Delhi: a cross-sectional study. Indian $\mathrm{J}$ Cancer. 2018;55(3):233.

5. Muñoz N, Bosch FX, de Sanjosé S, Herrero R, Castellsagué $\mathrm{X}$, Shah KV, et al. Epidemiologic classification of human papillomavirus types associated with cervical cancer. $N$ Engl J Med. 2003;348(6):518-27.

6. Roy S, Shankar A, Rath GK. HPV vaccination of girl child in india: intervention for primary prevention of cervical cancer. Asian Pac J Cancer Prev. 2018;19(9):2357-8.

7. Human Papillomavirus (HPV) Vaccines- National Cancer Institute. 2019. Available from: https://www.cancer.gov/about-cancer/causesprevention/risk/infectious-agents/hpv-vaccine-factsheet. Accessed on 19 July 2020.

8. Mishra GA, Pimple SA, Shastri SS. HPV vaccine: One, two, or three doses for cervical cancer prevention? Indian J Med Paediatr Oncol. 2015;36(4):201.

9. Swain D, Parida SP. Preparedness of young girls for prevention of cervical cancer and strategy to introduce the HPV vaccine. Indian $\mathbf{J}$ Community Med. 2018;43(5):38.

10. WHO. Human papillomavirus (HPV). WHO Available from: http://www.who.int/immunization/ diseases/hpv/en/. Accessed on 12 September 2019.

11. Sachan PL, Singh M, Patel ML, Sachan R. A study on cervical cancer screening using pap smear test and clinical correlation. Asia-Pac J Oncol Nurs. 2018;5(3):337-41.

12. The Federation of Obstetric and Gynaecological Societies of India. Available at: https://www. fogsi.org/fogsi-gcpr-on-screening-mangement-ofcervical-precancerous-lesions/. Accessed on 14 January 2020.

13. He J, He L. Knowledge of HPV and acceptability of HPV vaccine among women in western China: a cross-sectional survey. BMC Women's Health. 2018;18(1):130.

14. Mehta S, Rajaram S, Goel G, Goel N. Awareness about human papilloma virus and its vaccine among medical students. Indian J Community Med. 2013;38(2):92-4.

15. Das EN, Francis PT. HPV vaccine knowledge and coverage among female students in a medical college, Kerala. Int J Community Med Public Health. 2018;5(12):5133.

16. Singh J, Baliga SS. Knowledge regarding cervical cancer and HPV vaccine among medical students: a cross-sectional study. Clin Epidemiol Glob Health. 2020 .

Cite this article as: Sharma V, Bachhel $\mathrm{R}$, Singh NR. Human papilloma virus vaccines awareness among female medical and dental undergraduate students. Int J Basic Clin Pharmacol 2020;9:1820-3. 